\title{
Resenha
}

\section{OS 7 HÁBITOS DAS PESSOAS MUITO EFICAZES}

( Do autor: Stephen R. Covey, 35 ed. São Paulo: Best Seller, 1989)

Hidemburgo Gonçalves Rocha (1)

Lindeberg Rocha Freitas (2)

\section{Introdução}

Os 7 hábitos das pessoas muito eficazes, desde a sua criação, já passou por algumas atualizações e versões novas, como “ Os 7 hábitos das pessoas altamente eficazes”; Os 7 hábitos das famílias altamente eficazes", dentre outras. Porém, em todas elas, o autor se mantém fiel às suas idéias básicas.

A reflexão de fundo, da qual se baseiam todos os hábitos é a seguinte: em qualquer situação, a única pessoa que você poderá modificar é você mesmo. O melhor investimento que pode fazer, então, é melhorar a si mesmo, desenvolvendo os hábitos que farão de você uma melhor pessoa e melhor profissional.

Se você quer modificar qualquer situação, têm que se comportar de forma diferente. Mas para mudar seu comportamento, deve antes modificar seus paradigmas - sua forma de interpretar o mundo.

A idéia de Stephen Covey com "Os 7 hábitos" é apresentar uma nova forma para mudar paradigmas, ao instaurar novos hábitos que lhe permitirão escapar da inércia e atingir os seus objetivos.

Os três primeiros hábitos falam do auto-domínio. Isto é, estão orientados a conseguir o crescimento da personalidade para obter a independência.

Os seguintes três hábitos tratam das relações com os outros - trabalho em equipe, cooperação e comunicação; estão orientados a conseguir a interdependência.

Finalmente, o hábito sete, fala a sobre a renovação contínua que o levará a entender melhor os hábitos restantes. 


\section{Os hábitos}

Um hábito está na intersecção de três componentes: o Conhecimento, as Habilidades e o Desejo (ou atitude). O Conhecimento lhe indica o que fazer e por quê. As Habilidades lhe ensinam como fazer as coisas. O Desejo é a motivação, sua vontade de fazê-las.

Para converter-se em um comportamento, precisa dos três componentes.

\section{A efetividade e o equilíbrio P/CP}

Os 7 hábitos estão em harmonia com a lei natural chamada pelo autor de equilíbrio P/CP. Este princípio pode entender-se melhor com a conhecida fábula de Esopo:

Um dia, um fazendeiro pobre descobre um ovo de ouro no ninho da sua galinha. Ele não podia acreditar na sorte que teve. Porém, cada dia que passa, aparece um ovo novo, tornando-o milionário. Mas ao mesmo tempo, se torna cobiçoso e impaciente e decide matar a galinha para obter todos os ovos de uma vez, sem ter que esperar um dia após o outro. Mas, ao abrir a galinha, ele vê que não tem nenhum ovo de ouro dentro do corpo.

Este é um caso claro da lei da eficiência. Muitos pensam que ser eficiente é tirar todos os ovos tão rápido como seja possível. Mas para ser realmente eficiente, precisa dos ovos e da galinha que os produz.

Daí a necessidade de equilíbrio entre $\mathrm{P}$ (a produção, quer dizer os ovos) e a CP (a capacidade de produzir, ou seja, a galinha).

Em torno deste equilíbrio está o verdadeiro significado da eficiência em todas as áreas da sua vida. Este princípio se pode aplicar a qualquer tipo de situação: às pessoas que trabalham com você, às equipes que estão sob seu comando, sua saúde, suas finanças pessoais e suas relações com outras pessoas no seu lar ou no seu ciclo de amizade.

\section{Hábito 1 - Ser Proativo}

Ser pró-ativo significa tomar a responsabilidade por sua própria vida - exercitar a habilidade de selecionar sua resposta frente a qualquer estímulo. Isto implica comportar-se segundo sua decisão consciente, baseado nos seus valores, e não nas condições nas quais se encontra, nem na forma como foi criado, nem na sua carga genética. 
A liberdade na escolha da sua resposta se baseia em:

- Auto-consciência (self awareness): que lhe permite diferenciar-se do seu estado de ânimo, sentimentos e pensamentos.

- Imaginação: para criar idéias além da sua realidade presente

- Consciência: para distinguir o bem do mal

- Vontade independente: para atuar baseado na sua auto-consciência

Uma pessoa pró-ativa é guiada pelos seus próprios valores, a diferença da pessoa reativa, quem entrega o controle sobre suas decisões, deixando que o comportamento e as opiniões dos outros lhe digam como deve se sentir.

Uma vez que entenda esta diferença, ficará claro porque ninguém pode fazê-lo sentirse mal, a menos que você o permita.

Esta verdade, porém, não é fácil de aceitar, ainda mais se você está acostumado a colocar a culpa nos outros pelo seu azar e por seus problemas. Uma vez que admita "estou aqui pelas decisões que tomei ontem ", pode então declarar "escolho ser alguma outra coisa amanhã".

Uma chave para determinar se você é pró-ativo ou reativo está na linguagem que utiliza. Se você diz coisas como "o gerente de marketing me deixa raivoso", está sendo reativo - está permitindo que outro tome controle das suas emoções. O enfoque pró-ativo seria "estou permitindo que o gerente de marketing me deixe raivoso. Posso escolher responder de outra forma".

Para desenvolver sua pró-atividade, tente o seguinte:

- Ponha atenção às palavras que escolham você e os que o rodeiam . Com que frequência escuta expressões reativas como "tenho que..." em lugar de "quero..."?

- Identifique as debilidades dos outros, mas não como um pretexto para os seus próprios erros, e sim como oportunidades para escolher suas respostas.

- Trabalhe durante 30 dias praticando os princípios. Coloque especial cuidado naquelas coisas que possa controlar.

\section{Hábito 2 - Começar com o objetivo na mente}

Este é o hábito da liderança pessoal, que indica a necessidade de começar cada dia com um claro entendimento dos seus objetivos e destinos desejados. 
É necessário entender que todas as coisas são criadas duas vezes. Pense na construção de uma casa - antes de começar a construção, se desenha um plano (a primeira criação). Após isso, constrói a casa (a segunda criação). Nos negócios funciona igual: a primeira vez, você define o que deseja conseguir, depois disso desenha todas as partes do negócio para conseguir o objetivo.

Isto explica a diferença entre liderança e gerência. A liderança deve vir primeiro.

A liderança implica concentrar-se na pergunta "o que quero conseguir ?”, a diferença da gerência que se baseia em " qual é a melhor forma de conseguir o que quero ?”. O hábito 2 cobre o "o que quero conseguir" (liderança), e o 3 o "qual é a melhor forma" (gerência).

\section{Liderança X gerência - Um exemplo:}

Imagine um grupo de pessoas abrindo uma estrada pelo mato. O líder é a pessoa que sobe na árvore mais alta, olha ao redor, e declara "estamos no mato errado".

Os gerentes são as pessoas que seguem os trabalhadores que cortam o mato, e vão escrevendo os manuais de procedimento. A esses últimos não lhes importa se é o mato correto ou não, sempre e quando estejam progredindo no seu trabalho.

Para ser eficiente, não importa quanto se trabalhe no mato equivocado. Dai que a liderança deve ser primeiro, e a gerência vir depois.

Começar o dia com um fim em mente implica ter seus valores firmemente estabelecidos na sua mente, de forma a afrontar o desafio, de tomar decisões que se derivem deles. Você pode fazer isto, escrevendo um enunciado de missão pessoal- não para sua empresa, para você. Faça uma lista dos princípios pelos quais você vive e trabalha. Por exemplo: "escutar as duas partes antes de tomar uma decisão; defender aos que não vieram; pedir a opinião dos outros" e assim sucessivamente. Utilize este enunciado como base para todas as decisões que tome.

\section{Seu centro}

Para escrever este enunciado, deve primeiro explorar seu centro (ou núcleo), o qual está conformado pelos seus paradigmas básicos - a lente que usa para ver o mundo. Qualquer que seja seu centro, será sua fonte de segurança (sentido do valor e auto-estima), guia (princípios que utiliza para controlar suas decisões), sabedoria (seu juízo e perspectiva da vida) e poder (habilidade para atuar e conseguir o que deseja).

Seu tipo de centro indicará o tipo de comportamento e de decisões que tome. Estes são alguns dos centros comuns, e as razões que podem impedi-lo de ser eficiente. 
- Centrado no seu cônjuge ou sua família: obtém seu sentido de segurança e valor pessoal do seu matrimônio e filhos. Mas ter problemas com a sua família, pode afetar sua auto-estima. Além disso, pode preocupar-se demais por ser popular com seus filhos, em lugar de ensinar-lhes auto-disciplina.

- Centrado no dinheiro ou no seu trabalho: sua segurança vem da quantidade de dinheiro que tem ou da quantidade de trabalho que faz. Uma pequena ameaça a seu ingresso, ou um problema de trabalho, podem derrubar sua vida.

- Centrado em posses: sua segurança provém de ter casas, veículos, barcos etc. Como você equipara o seu valor pessoal com o valor do que você possui, seu valor varia constantemente. Se está em presença de alguém com mais posses ou maior status, você se sente inferior.

Cada um destes centros é volátil e pouco consistente. Se você possui um deles, você dá a outro o poder sobre suas decisões e comportamento.

O hábito 2 fala sobre conseguir o centro adequado - um centro baseado em princípios, que não mudam, nem tem horizonte de tempo. Sua segurança provirá de saber que não mudam. À diferença do seu cônjuge ou familiares, os princípios não morrem ou solicitam divórcio. À diferença do dinheiro ou dos bens, os princípios não podem ser roubados ou perdidos.

\section{Seu comportamento e os centros - Um exemplo:}

Imagine que é o fim do dia de trabalho, e prometeu a sua esposa levá-la a um concerto - A última hora, seu chefe lhe pede, por favor, que fique trabalhando até tarde, para ajudá-lo a preparar uma apresentação.

- Se você esta centrado no seu cônjuge ou família, sua esposa vem primeiro. Dirá ao seu chefe que não pode.

- Se você esta centrado no dinheiro, pensará no dinheiro que conseguirá por trabalhar horas extras,e deixará sua esposa em casa.

- Se está centrado no trabalho, terá a oportunidade de ganhar pontos com seu chefe. Você esperará que sua esposa se sinta orgulhosa por você ter trabalhado duramente.

- Se está centrado em posses, traduzirá as horas de sobre-tempo em algo que se possa comprar. Se o que pode comprar vale mais do que as entradas para o concerto, você fica. 
Uma pessoa centrada em princípios avalia as opções sem os preconceitos ou emoções dos outros centros. Levará todos os fatores em consideração e procurará a solução que melhor se adapte a suas necessidades.

Há cinco diferenças importantes na hora de tomar uma decisão baseada em princípios:

1.- Você toma a decisão pró-ativamente, baseado no seu sentido da razão, e não porque alguém o empurre numa direção ou outra

2.- Você sabe que sua decisão é a adequada, porque está baseada em princípios com resultados previsíveis a longo prazo

3.- Sua decisão contribui a reforçar os seus valores

4.- Pode comunicar-se honestamente com as partes envolvidas, porque tem desenvolvido relações interdependentes com eles

5.- Se sente confortável com sua decisão, seja ela qual for.

\section{Hábito 3 - Primeiro o mais importante}

No hábito 1 , aprendeu que pode criar seu próprio paradigma. No hábito 2 , descobriu os princípios básicos pelos quais deveria viver e trabalhar. Uma vez aprendido isto, estará pronto para colocar primeiro o primeiro cada dia, a cada momento. Em outras palavras, praticar os princípios da administração pessoal.

O hábito 3 nos leva ao campo do controle do tempo. Para ser realmente efetivo, é necessário organizar seu tempo ao redor das suas prioridades.

Considere o seguinte quadro, que toma em conta dois fatores: 1) Importância - que tão crítica é uma atividade para sua missão e seus valores, 2) Urgência - que tão insistentemente precisa da sua atenção.

\begin{tabular}{|c|c|c|}
\hline & Urgente & Não Urgente \\
\hline Importante & I & $\begin{array}{l}\text { II } \\
\text { Prevenção, Relações, Planificação, } \\
\text { Recreação }\end{array}$ \\
\hline $\begin{array}{l}\text { Não } \\
\text { importante }\end{array}$ & $\begin{array}{l}\quad \text { III } \\
\text { Interrupções, ligações, atividades } \\
\text { populares }\end{array}$ & $\begin{array}{l}\text { IV } \\
\text { Algumas ligações, algum e-mail, } \\
\text { atividades de lazer }\end{array}$ \\
\hline
\end{tabular}

Toda atividade no quadrante I é importante e urgente, tal como uma crise, uma reunião chave para um projeto, etc. 
Uma atividade no quadrante II é importante, mas não urgente. Inclui atividades de manutenção, aprendizagem contínua, planificação estratégica, construção de relações etc.

No quadrante III, as atividades são urgentes, mas não importantes. O telefone tocando, ou um e-mail, exigem sua atenção, mas não estão conectadas com suas prioridades.

Finalmente no quadrante IV estão as atividades que não são nem urgentes nem importantes - tarefas que o mantém ocupado, sem conseguir nada.

As pessoas que passam a maior parte do seu tempo no quadrante I vivem uma crise trás outra. quando sobrevivem a uma crise, tem outra esperando por eles. Para escapar da pressão, passam ao quadrante IV a perder o tempo, o qual aumenta o nível de estresse antes de voltar para o quadrante I.

Outras pessoas freqüentam o quadrante III, controlando atividades urgentes, mas não importantes. Lembre-se que estas atividades são urgentes só porque são importantes para outro.

A pessoa eficiente evita os quadrantes III e IV, trata de minimizar as atividades do quadrante I, para passar a maior parte do seu tempo no quadrante II (este último é muito fácil de evadir, por que não é urgente).

Para mostrar isto, pergunte-se que atividade poderia realizar em forma regular que melhoraria significativamente a sua vida no trabalho ? Com certeza a resposta será alguma coisa como "melhorar as relações com os meus colegas "ou outra similar no quadrante II.

\section{Como organizar seu tempo para o quadrante II}

1.- Faça uma lista de todos os seu papéis.

Exemplo: Marido, Pai, Gerente de novos produtos, Presidente de uma associação benéfica etc.

2.- Selecione seus objetivos para a próxima semana. Pense em 2 o 3 resultados importantes que queira alcançar para cada um dos seus papéis. Certifique-se de que estejam no quadrante II, e que estejam ligados aos seus objetivos a longo prazo.

Exemplo: no papel de Gerente de Novos Produtos, seus objetivos poderiam ser : fazer a análise do estudo de consumidores e entrevistar candidatos para assistente.

3.- Separe o tempo para trabalhar com cada objetivo. Identifique com precisão seus espaços de tempo, e faça encontros concretos com outras pessoas.

(Pode conseguir folhas de trabalho para organizar a sua semana e outras ferramentas visitando a página web de Franklin Covey - http://www.franklincovey.com). 


\section{Hábito 4 - Pense em vencer-vencer}

Os hábitos do 1 ao 3 tratam de "vitórias privadas", como trabalhar com você para desenvolver o seu caráter. Os hábitos 4 ao 6 o levaram a "vitorias públicas", como desenvolver a personalidade para ter sucesso trabalhando com outras pessoas.

O hábito 4 implica que ambas partes em qualquer acordo devem sair beneficiadas. Está baseado no paradigma segundo o qual a vitória de uma pessoa não necessariamente acontece as custas da derrota de outra.

A alternativa a ganhar/ganhar é perder/perder. Si um ganha e o outro perde, nenhum dos dois obtém a confiança e lealdade do outro a longo prazo. Quer dizer, você pode ganhar fazendo a outra parte perder, mas isso afetará a próxima negociação.

Se não pode alcançar um trato ganhar/ganhar, é preferível não fazer o trato. Pelo menos manter a relação, abrindo o campo para um acordo ganhar/ganhar no futuro.

Ganhar/ganhar implica cinco elementos ou dimensões:

1.- Caráter: é a base do paradigma ganhar/ganhar, desenvolvendo os hábitos de 1 ao 3. Só quando conhece bem os seus valores, saberá o que significa ganhar para Você. Além do mais terá a integridade para manter suas promessas aos outros.

2.- Relações: se constroem sobre a base do caráter. Trabalha desenvolvendo sua credibilidade ao longo do tempo, estará investindo em relações abertas ao sucesso de ambas partes.

3.- Acordos: os acordos surgem a partir das relações. Devem ter cinco elementos muito explícitos para deixar claras as expectativas: resultados desejados, regras ou parâmetros dentro das quais se obterão esses resultados, recursos disponíveis para conseguir os resultados, medidas para avaliação dos objetivos alcançados e as consequências que perseguem os objetivos.

4.- Sistema: para que os acordos funcionem, o sistema deve estar em capacidade de controlá-lo. Inclui sistemas para capacitação, planificação, comunicação, informação etc.

5.- Processo: um processo de quatro passos deve ser utilizado para conseguir um acordo ganhar/ganhar:

- Tente ver a situação desde a perspectiva do outro

- Identifique os aspectos e preocupações-chave

- Faça uma lista de resultados que consideraria uma solução aceitável

- Busque novas opções para obter esses resultados 
Para que este processo funcione, precisa dos hábitos 5 e 6 .

\section{Hábito 5 -Procure primeiro compreender, depois ser compreendido}

Este é o hábito da comunicação efetiva. É também o hábito mais emocionante, e que podem colocar em funcionamento de forma imediata.

A maioria das pessoas passam sua vida aprendendo a se comunicarem em forma escrita ou falada, mas tem pouco treinamento em escutar - em entender verdadeiramente a outra pessoa desde seu próprio marco de referência.

É pouco comum a pessoa que escuta com a intenção de entender. Geralmente se escuta com a intenção de responder.

Escutar com empatia é uma ferramenta muito poderosa - lhe proporciona informação exata com a qual trabalhar. Em lugar de filtrar o que a pessoa fala pelo filtro com o qual você olha o mundo (ou mais bem escuta), tem que entender como a outra pessoa o vê.

Depois da necessidade física de sobreviver, a necessidade mais importante de uma pessoa é a de sobreviver psicologicamente - ser entendido e apreciado. Ao escutar com empatia, você estará satisfazendo essa necessidade (segundo Covey,está lhe dando "ar psicológico"). Uma vez que a pessoa tenha suas necessidades básicas cobertas, baixa as suas defesas, e pode então influenciá-lo e trabalharem juntos numa solução ganhar/ganhar.

\section{Hábito 6 - Sinergizar}

Sinergia significa que o todo é mais do que a soma das suas partes.

O hábito de sinergizar implica então a cooperação criativa e o trabalho em equipe: as pessoas com mentalidade ganhar/ganhar, e que escutam com empatia, podem aproveitar suas diferenças para gerar opções que não existiam antes.

Reunir várias perspectivas diferentes, no espírito do respeito mútuo, traz como resultado a sinergia. Os participantes sentem a liberdade de procurar a melhor alternativa possível, e com freqüência conseguem propostas diferentes e melhores que as originais.

A sinergia é um método para resolver problemas baseado em recursos humanos, em contraposição com o método baseado em relações humanas. Este último é utilizado por 
pessoas inseguras que tendem a ter em volta gente que pense igual e que constantemente tendem a concordar ou aprovar tudo o que se diga. Confundem uniformidade com unidade.

\section{Hábito 7 - Afiando o instrumento}

É o hábito da auto-renovação, a manutenção básica necessária para manter os hábitos restantes funcionando adequadamente.

A efetividade, como falávamos anteriormente, se consegue quando se pode manter o equilíbrio entre a produção $(\mathrm{P})$ e a capacidade de produção $(\mathrm{CP})$. Porém, é frequente que as pessoas estejam demasiado ocupadas produzindo (serrando) para prestar atenção à manutenção do seu meio de produção (afiar a serra). A razão pela qual isto ocorre é que a manutenção poucas vezes produz dividendos importantes de forma imediata.

Afiar a serra implica a invenção de um programa balanceado, sistêmico, para a autorenovação em quatro áreas fundamentais. Deve dedicar pelo menos uma hora cada dia trabalhando nelas:

- Dimensão física: inclui exercício físico, nutrição e controle do Stress. Ao comer adequadamente, e exercitar-se 30 minutos por dia, conseguirá melhorar sua força e resistência em forma pró-ativa. Se não o fizer, seu corpo se debilitará.

- Dimensão espiritual: renovar seu compromisso com seus valores (do hábito 2) pelo meio da revisão da sua missão pessoal, ou por meio do rezo, meditação, ou imersão em música, literatura, ou natureza. Se não o fizer, seu espírito será insensível.

- Dimensão mental: sua mente se "afia" por meio de atividades como leitura, escritura e planejamento. Também se consegue seguindo os hábitos 2 e 3, começar com um fim em mente e colocando primeiro o primeiro. Se não o fizer, sua mente funcionará como uma máquina.

- Dimensão social/emocional: enfocar-se nos hábitos 4, 5 y 6, utilizando-os nas interações diárias com os outros.

Como as quatro dimensões estão interrelacionadas, o que faça para "afiar a serra" numa, impactará positivamente nas outras. Se trabalha equilibradamente nas quatro, passando pelo menos uma hora ao dia, todos os dias, fará dos hábitos uma parte fundamental da sua vida.

Fazê-lo toma tempo e dedicação. Depois de tudo, são os hábitos da gente eficiente, os que conseguem o sucesso ao fazer aquelas coisas que muitos tentam evitar. 
Comece a trabalhar nos hábitos, de uma vez. Comece com o primeiro hábito: seja próativo. Depois continue com suas vitórias privadas - concentre-se em princípios e foque-se em atividades do quadrante II. Depois continue com as vitórias públicas - Procure situações ganhar-ganhar, escute empaticamente, e sinergize. Mas lembre-se, este processo criativo nunca acaba. Deve continuar afiando esses instrumentos pelo resto da sua vida.

\section{Sobre os autores:}

(1) Hidemburgo Gonçalves Rocha é Mestre em Bioquímica e Professor Adjunto da Universidade Regional do Cariri e da Universidade Federal do Ceará, atuando na Faculdade de Medicina do Cariri. E_mail: hidemburgo.rocha@bol.com.br.

(2) Lindeberg Rocha Freitas é Doutor em Ciências e Tecnologia dos alimentos. 